\title{
Clinical outcomes of intracranial complications secondary to acute otitis media: The Alder Hey Experience
}

Krishnan M, Walijee H, Jesurasa A, De S, Sinha A, Donne A \& Sharma R.

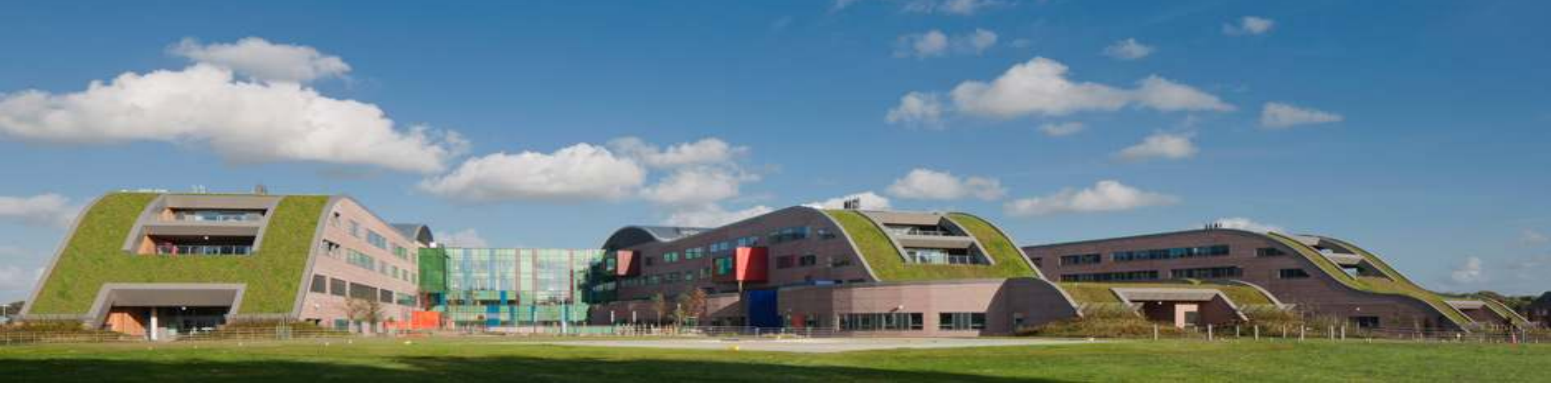

\section{Conclusion}

A wide variation in management did not result in altered clinical outcomes. It was felt that there was no real consensus over anticoagulation for patients with sinus thrombosis. A prospective national study is required to be able to reach a consensus on managing these often complex patients.

\section{Introduction}

Acute mastoiditis is the most common intra-temporal complication of otitis media. Its management remains a challenge due to potential extracranial and intracranial complications. This study was designed to evaluate the recent experience of acute mastoiditis with intracranial complications at a tertiary paediatric centre.

\section{Method}

A retrospective case note review was carried out for patients admitted to Alder Hey Children's Hospital between January 2006 and December 2016. Patients were identified using ICD-10 codes H700, H701, H702, $\mathrm{H} 708$ and $\mathrm{H} 709$. Patients with intracranial complications were identified following review of notes.

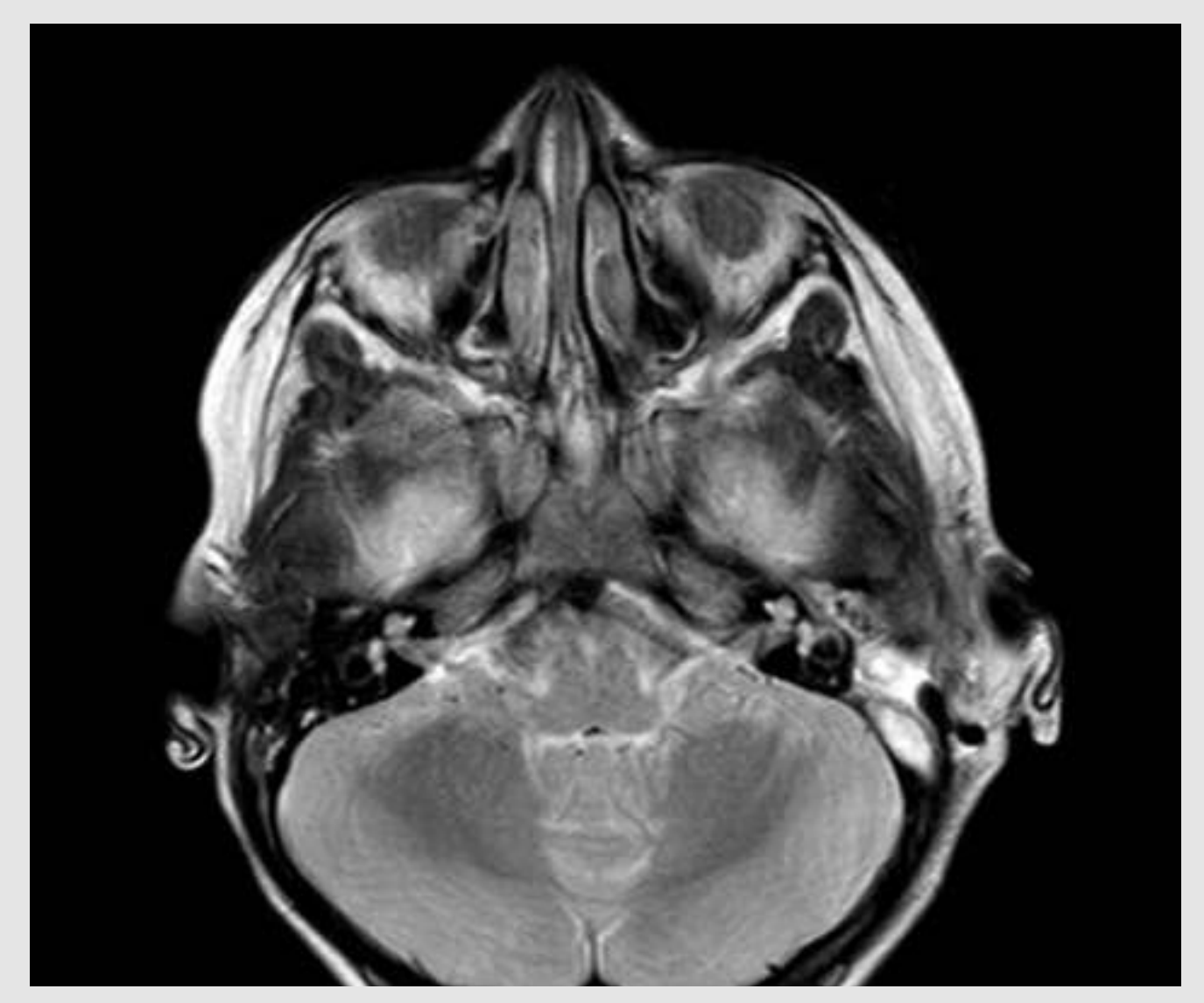

Figure: Axial MRI head demonstrating left mastoiditis with an associated intracranial abscess

\section{Presenting signs/symptoms}

$\begin{array}{lll} & \begin{array}{l}\text { Number of } \\ \text { patients }\end{array} & \begin{array}{l}\text { \% of total } \\ \text { patients }\end{array} \\ \text { Otalgia } & 19 & 63 \\ \text { Vomiting } & 19 & 63 \\ \text { Fever } & 17 & 57 \\ \text { Drowsiness } & 14 & 47 \\ \text { Headache } & 13 & 43 \\ \text { Otorrhoea } & 12 & 40 \\ \text { Mastoid swelling } & 8 & 27 \\ \text { Diplopia / Squint } & 8 & 27 \\ \text { Seizures } & 4 & 13 \\ \text { Mastoid tenderness } 2 & 7 \\ \text { Facial weakness } & 2 & 7 \\ \text { Photophobia } & 2 & 7 \\ \text { Neck stiffness } & 1 & 3\end{array}$

\section{Results}

30 patients were identified with mastoiditis and associated intracranial complications, with 17 males and 12 females. The average age was 4 years and 2 months (range 2 months -15 years. $53 \%$ of patients were investigated with a combination of CT and MRI scans. $73 \%$ were diagnosed with sinus thrombosis, $40 \%$ cerebral abscess and $33 \%$ subperiosteal abscess. $78 \%$ of the patients required surgical intervention. Of the 22 patients with sinus thrombosis, 9 received anticoagulation. 27 patients recovered fully with no significant long term sequelae following an average of 50 months follow-up. 